\title{
Parelles lingüístiques als centres educatius del Baix Empordà seguint el model del Voluntariat per la Llengua del Consorci per a la Normalització Lingüística
}

\author{
Marta Silvestre \\ Assessora LIC del Baix Empordà \\ msilvest@xtec.cat
}

\author{
Anna Fuentes \\ Coordinadora LIC de l'Institut Puig Cargol \\ afuente9@xtec.cat
}

Rebut: 24 de febrer de 2021

Acceptat: 2 de juny de 2021

\begin{abstract}
Resum
L'experiència consisteix a adaptar l'activitat de parelles lingüístiques ideada pel Consorci per a la Normalització Lingüística en el marc del Voluntariat per la Llengua per portar-la a terme amb l'alumnat nouvingut i els voluntaris dels centres de primària i secundària participants. Es tracta d'una activitat complementària al treball d'aprenentatge de la llengua catalana a les aules d'acollida o com a suport lingüístic.
\end{abstract}

\section{Introducció}

Des que el Departament d'Educació va crear les aules d'acollida, en el marc del Pla per a la Llengua i la Cohesió Social (LIC) fa setze anys, al Baix Empordà vam iniciar el Voluntariat per la Llengua $(\mathrm{VxL})$ als nostres centres educatius, una activitat de parelles lingüístiques com a suport al treball d'aquestes aules. La zona de Torroella de Montgrí-L'Estartit va ser la primera del Baix Empordà en la qual van participar en el projecte de parelles lingüístiques tots els centres de primària i secundària. De mica en mica, l'equip LIC vam anar treballant juntament amb tot l'equip del Consorci per a la Normalització Lingüística (CPNL) del Baix Empordà i podem dir que aquesta activitat s'ha portat a terme amb molt de gaudi i aprenentatge a la Bisbal d'Empordà, Sant Feliu de Guíxols, Calonge-Sant Antoni, Santa Cristina d'Aro i molts altres municipis de la zona.

Tant a primària com a secundària l'activitat es porta a terme setmanalment al llarg del segon trimestre (de gener a març) i té un durada de 10 a 12 sessions. L'activitat que presentem funciona bé a totes dues etapes, tot i que amb petites diferències: 
- A primària es proposa com a aprenent tot l'alumnat nouvingut ${ }^{1} \mathrm{i}$ es demanen com a voluntaris només alumnes del cicle superior, perquè en aquesta etapa hi ha molts alumnes que hi volen participar. En general, a primària sempre hi ha molts més voluntaris que aprenents i això és positiu.

- A secundària, els alumnes són més conscients del que representa l'activitat, la proposem a tot l'alumnat nouvingut i busquem voluntaris entre les tutories d'ESO. En general, no tenim problemes i ens surten parelles equilibrades. Gairebé sempre, tots els alumnes nouvinguts hi participen, però, com que és una activitat voluntària, pot ser que algun no hi tingui interès. Si després d'explicar bé als alumnes els beneficis de participar a l'activitat hi segueixen renunciant, ho respectem, però la majoria, tot i ser una activitat voluntària, s'hi volen implicar.

Els objectius d'aquest projecte són, per una banda, complementar el procés d'aprenentatge de la llengua oral de l'alumnat nouvingut dels centres participants, amb aula d'acollida o sense, i afavorir la convivència, la interculturalitat i la integració al grup classe, al centre i al municipi de l'alumnat implicat. Per altra banda, es pretén donar a conèixer el Voluntariat per la Llengua entre la comunitat educativa i promoure el treball en xarxa.

\section{Estructura de l'activitat}

Segons els cursos i els municipis, el nombre de centres que formen part del projecte va variant i mirem de vincular l'activitat als plans educatius d'entorn i al treball educatiu en xarxa municipal. Tot i que a cada municipi hi ha variants, en general seguim una estructura comuna que serveix de base per planificar l'activitat.

A finals del primer trimestre detectem els centres que volen participar al VxL de cada municipi i mirem d'engrescar-los a tots. A continuació, fem una primera reunió de coordinació per planificar l'activitat, on assisteixen un representant de cada centre (CLIC), una representant tècnica de l'Ajuntament, una representant del CPNL i l'assessora LIC de la zona. Des del centre, que coneix bé l'alumnat, es proposa la llista de parelles. Cada centre s'organitza de la manera que li resulta més còmoda, però habitualment els aprenents es troben amb l'alumnat nouvingut i els voluntaris es proposen des de les tutories.

A l'inici del segon trimestre fem un acte d'inauguració a cada centre, normalment a la biblioteca. Hi assistim els membres de la comissió i, sovint, la direcció. En aquest acte es presenten les parelles i es donen pautes per al bon desenvolupament de l'activitat i algun material lúdic per estimular la conversa durant les sessions, tot i que sempre es té en compte que, si la conversa flueix lliurement, no calen materials. Una vegada iniciada l'activitat, la comissió es troba per fer una segona reunió de coordinació per tal de preparar la cloenda.

A l'inici del tercer trimestre, arriba l'acte més esperat per tothom, la cloenda, on ens reunim tots els voluntaris, aprenents i organitzadors. Si hi ha més d'un centre, ens trobem en els teatres i espais municipals. Aquest dia els alumnes se senten molt especials: ens parlen de la seva experiència; participen d'espectacles que han preparat com, per exemple, actuacions musicals en català, $i$, fins i tot, en una ocasió, a Calonge, vam poder gaudir de números de circ. Als alumnes els fa molta il.lusió rebre del CPNL el diploma que els reconeix com a participants en el VxL i un petit obsequi com a mostra d'agraïment.

1 Alumnat incorporat al sistema educatiu de Catalunya en els darrers 24 mesos o 36 en casos d'alumnes de cultures més allunyades. 


\section{Materials}

Tot i que a les darreres sessions s'arriba a la conversa lliure i a una bona amistat entre les persones que formen parelles i grups de conversa, de vegades, cal algun material per tal de trencar el gel al començament. És per això que, al llarg dels anys, els membres de la comissió hem treballat amb diferents guies de conversa. A la figura 1 teniu un exemple de les que s'utilitzen a l'Institut Puig Cargol de Sant Antoni de Calonge. A primària les guies solen ser més simplificades i amb més imatges adequades a l'edat.

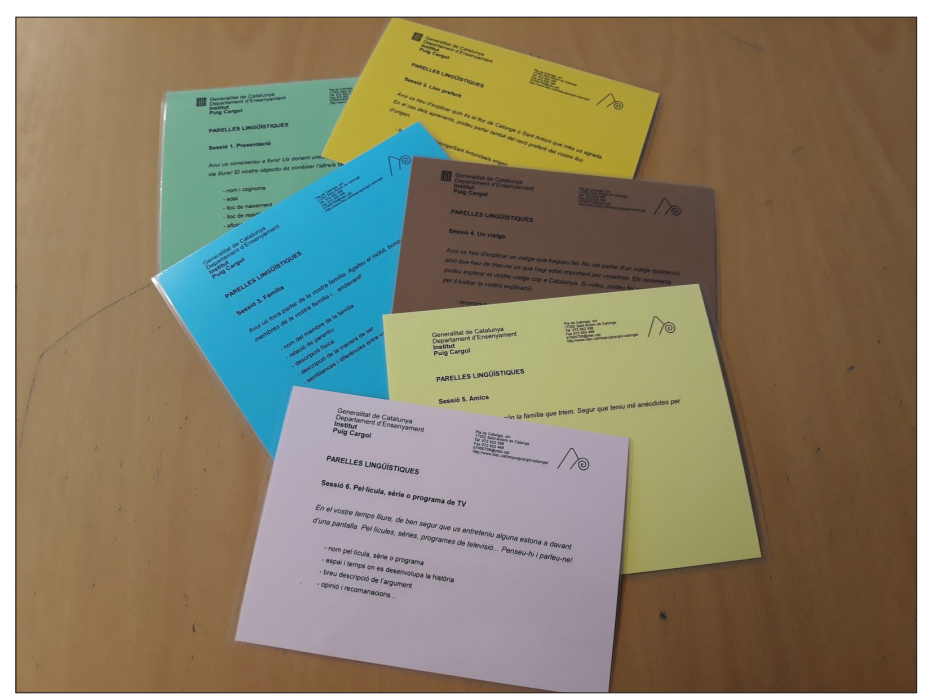

Figura 1. Guies de conversa de l'Institut Puig Cargol de Sant Antoni de Calonge

S'ha escollit un tema diferent per a cada sessió: presentació; lloc preferit; família; un viatge; amics; pel-lícules, sèries o programes de televisió; un objecte especial; l'institut; preferències musicals; plats típics, i plans de futur. De vegades alguns alumnes comencen a parlar seguint el guió pel gust de seguir una activitat guiada i després acaben la sessió lliurement. A més, des de la comissió també els orientem donant-los algunes idees per ajudar-se en la conversa, com portar fotografies digitals o impreses per il.lustrar la informació que van donant i fer coneixença amb la seva parella o grup de conversa. A primària també s'utilitza sovint el suport de jocs de taula.

\section{Punts forts i algun punt feble}

L'activitat de parelles lingüístiques sempre és molt ben valorada, sobretot perquè l'alumnat nouvingut té alumnes de referència al centre a qui es pot dirigir per resoldre qualsevol dubte i amb qui estableix un vincle de confiança. Fins i tot es pot arribar a generar un vincle d'amistat entre les persones que formen el grup, la qual cosa facilita la integració de l'alumnat nouvingut al nou centre i també pot ajudar l'alumnat del centre a generar noves relacions socials.

És evident que els estudiants del centre que participen a l'activitat com a voluntaris es consciencien de les dificultats que suposa per a l'alumnat nouvingut arribar a un país nou. Així doncs, l'activitat, entesa com a voluntariat, contribueix, també, a fomentar la consciència social i ciutadana dels alumnes per tal que es converteixin en ciutadans implicats en la seva comunitat.

Quan pensem en els participants de les parelles lingüístiques, també cal tenir en compte que assistir a aquesta conversa entre iguals un cop per setmana promou la responsabilitat. No sempre és fàcil mantenir el compromís i això és un aprenentatge que no hem d'oblidar. Finalment, cal afegir que el fet que els infants i joves nouvinguts portin a terme l'activitat amb tanta satisfacció pot afavorir un acostament molt positiu al Voluntariat per la Llengua i la 
possible participació de les seves famílies als programes de català per a adults.

Val a dir que, malgrat que l'activitat té èxit, sempre hi ha algun aspecte millorable. Alguns dels alumnes comencen parlant en llengua catalana però, per tal de facilitar el vincle amb l'alumnat nouvingut, fan servir altres llengües que els facin sentir més còmodes. En aquest sentit, és important la supervisió dels responsables de l'activitat per promoure el canvi d'actitud i que es recuperi la conversa en català, tal com es va orientar en l'acte d'inauguració.

Alguns centres comenten que se'ls fa difícil incorporar l'activitat per manca de temps. Consideren que el temps lliure dels alumnes a l'hora del pati no s'ha d'ocupar amb cap activitat. Per aquest motiu, en alguna ocasió s'ha fet l'activitat en horari lectiu, però, als centres on s'ha aplicat aquesta organització, l'activitat no ha tingut continuïtat, tot i tenir una valoració positiva.

\section{Comentaris finals}

Després de tants anys de portar a terme l'activitat als centres de la comarca, hem vist molts aprenents convertits en voluntaris, hem vist les mirades sorpreses de molts alumnes en els actes d'inauguració i hem xalat, com no us podeu imaginar, als actes de cloenda. És en aquestes celebracions on, a més a més de les activitats, donem veu a diferents parelles perquè ens expliquin la seva experiència. En aquest moment podem veure de primera mà el vincle d'amistat que s'ha establert entre l'alumnat, la millora lingüística, així com un cert sentit de pertinença a quelcom més gran que ens emociona i que potser ens costa de definir, però que podríem resumir constatant que formem part d'un tot ara que ja compartim la mateixa llengua.

Per això, ens ha semblat que aquest article pot donar testimoni de tot aquest treball $\mathrm{i}$, alhora, tenir tota aquesta informació per escrit ens pot servir, en els propers cursos, per donar una nova embranzida a l'activitat, que, com gairebé tot, ha patit un fort retrocés en aquest curs de pandèmia. Així doncs, només ens queda expressar un desig: per molts anys a les parelles lingüístiques als centres educatius!

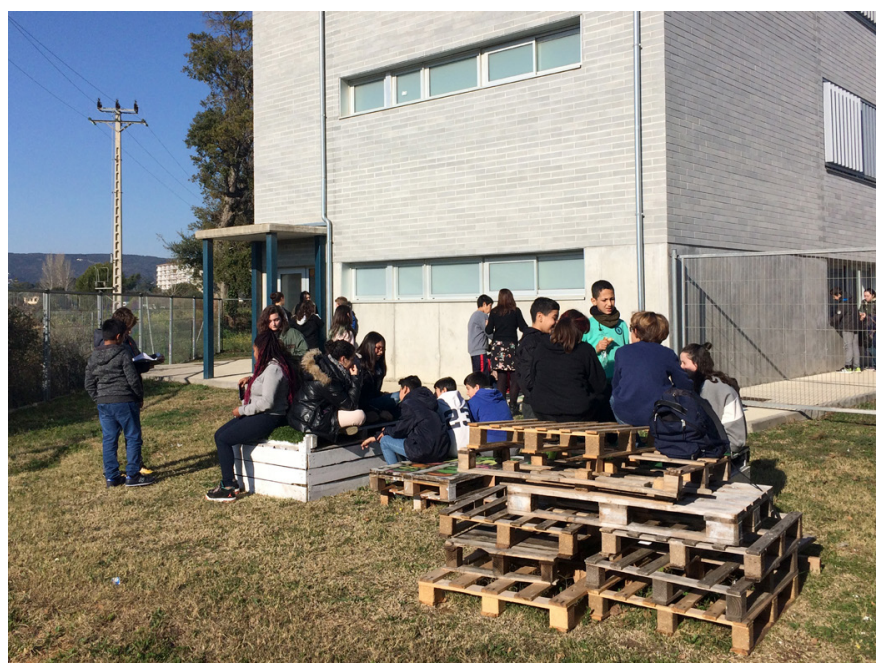

Figura 2. Grups de conversa al pati de l'institut Puig Cargol 